Indexaciones: Repositorio de Revistas UCR, DIALNET, Latindex, REDALYC Directorio y recolector de recursos digitales del Ministerio de Cultura de España, Directory of Open Access Journals. Diálogos Revista Electrónica de Historia ISSN 1409-469X. Número especial 2008. Dirección web: http://historia.fcs.ucr.ac.cr/dialogos.htm

\section{Historia y Literatura un proyecto interdisciplinario}

Apartado Postal 1394

Tel 00-52-222-2330049 y 00-52-222-295500 ext. 3137

lorencarr@yahoo.com Instituto de Ciencias Sociales y Humanidades Benemérita Universidad Autónoma de Puebla. 


\title{
HISTORIA Y LITERATURA, UN PROYECTO INTERDISCIPLINARIO
}

\author{
Ana Lorena Carrillo \\ Instituto de Ciencias Sociales y Humanidades \\ Benemérita Universidad Autónoma de Puebla
}

\section{Historia y Literatura}

El debate sobre las relaciones entre estas dos disciplinas suele poner en el centro de la atención el tema de la verdad y el de la verosimilitud. El punto de partida arranca del hecho de que la historia escrita, tiene pretensiones de verdad, mientras que los géneros literarios solamente la simulan y proponen escenarios irreales pero plausibles; verosímiles, pero no verdaderos. Por ese camino, la discusión se cierra muy pronto y múltiples opciones se quedan por el camino. Es bien cierto que sobre el tema de las relaciones entre verdad y ficción hay todo un campo de discusión que en gran medida atañe con mayor propiedad a la literatura y no tanto a la historia ni a sus relaciones. Así por ejemplo, partiendo de Platón, y su distinción entre el modelo y el simulacro, Tomás Eloy Martínez ${ }^{1}$, el autor argentino de novelas históricas y también profesor universitario, elabora la idea de una franja intermedia entre la verdad y la ficción a la que llama "ficciones verdaderas", la cual desarrolla partiendo también de complejizar la dicotomía "verdad/imaginación" a la que hacíamos referencia arriba a partir de categorías y conceptos que relativizan la oposición radical:

Un antiguo saber común supone, con cierta simpleza, que la literatura es el lugar de la imaginación y que el periodismo o la historia son los lugares de la verdad. Los conceptos de representación, de verosimilitud y lo que Roland Barthes llamaba

"la ilusión referencial" mezclan los tantos y sitúan la verdad en cualquier parte o en

1 Martínez, Tomás Eloy, “Ficciones verdaderas”, Letras libres, julio 2005, pp 42-47 
ninguna

Avanzando más allá de esa variante del debate, inician los problemas y los desafíos planteados por el proyecto interdisciplinario que explora las relaciones entre ambas disciplinas en las que se discute ya no las relaciones entre Verdad y Ficción sino entre las de Historia y Ficción, Historia y Narración, Literatura y Sociedad, Texto Histórico y Texto Literario, entre otras. Para empezar, el género historiográfico es también un género discursivo que se realiza narrativamente, es una narración. La Historia es simultáneamente tanto los hechos y acontecimientos irrepetibles y fugaces, como el relato con sus estructuras narrativas que da cuenta de ellos, los organiza y los hace inteligibles. Pensar de este modo la "heteronomía de la historia" como llamó Jacques Rancière $^{2}$ a esa duplicidad ,establece un terreno distinto a la de la verdad y la verosimilitud y abre las posibilidades de exploración a enfoques y temáticas más ricas y complejas.

Para los historiadores y filósofos de la historia la discusión no es en realidad reciente: Desde las ya clásicas obras de Hayden White, especialmente Metahistoria de 1973 y La operación historiográfica de Michel de Certeau publicada en 1975, hasta Tiempo y Narración de Paul Ricoeur de 1983/85 y Los nombres de la historia de Jacques Rancière de 1992, el tema ha acompañado en paralelo el desarrollo de la historiografía y su consolidación como historia “científica”a partir de la escuela de los Annales. De hecho ya desde1955 un artículo de Paul Ricoeur ponía énfasis en la condición "necesariamente equívoca” del lenguaje de la historia, refiriéndose a la inevitable conjunción en ella de los lenguajes de la imaginación y la narración por un lado y la ciencia y la precisión, por otro ${ }^{3}$. Incluso es desde 1949 que este autor aborda 2 Rancière, Jacques, Los nombres de la historia

3 El artículo en cuestión, "Objectivité et Subjectivité en historie”, Historie et Vérité, Paris, 1955, p.30 es citado en Bebiano, Rui, «Sobre a história como poética» en As Oficinas da 
en una inicial publicación este tema que habría de continuar desarrollando a lo largo de su vasta trayectoria intelectual. ${ }^{4}$ La reflexión sobre los vínculos entre historia y literatura, que se centra en el aspecto de la narración, se inscribe generalmente en el proceso señalado de crítica y reformulación periódica que la disciplina realiza respecto de sus propios métodos, límites y eficacia. La reevaluación del estado de la práctica histórica luego de décadas de predominio de las corrientes cientificistas ha venido realizándose en el contexto de una gran revitalización de los estudios sobre la cultura, los cuales han extendido su influencia a un gran espectro de disciplinas sociales y humanísticas. Dicha reevaluación ha llegado a conclusiones que van desde la equilibrada valoración que confirma la pertenencia de la historia a las ciencias sociales, pero que al mismo tiempo propone una mayor apertura hacia paradigmas interdisciplinarios; hasta el otro extremo, con propuestas que ponen en duda la capacidad de la historia para generar conocimiento "verdadero" acerca del pasado y su concepción como mero discurso en igualdad de condiciones y términos que el discurso de la ficción. El justificado temor entre los historiadores por lo que podría entenderse como un "suicidio"disciplinario de cara a las respuestas más extremas que serían por un lado, las de insistir en la separación tajante entre "ciencia" y "relato" y por otro, la de confundir historia y ficción, ha resultado en un saludable debate en torno a la condición actual y las perspectivas de la historia y la escritura de la misma. En América Latina, la historiografía, usualmente tributaria de los desarrollos teóricos norteamericanos y europeos sigue de cerca el debate y reconfigura especialidades historiográficas acordes a las normas del canon vigente: historia cultural e intelectual, de las mentalidades, etc. No obstante, es importante señalar que en la práctica historiográfica local, una larga tradición de escritura de la historia que viene desde el

História, coord. de José d'Encarnação. Lisboa, Edições Colibri - Faculdade de Letras da Universidade de Coimbra, pp. 47-70.

4 Vergara, Luis, "Paul Ricoeur y la escritura de la historia",Fractal 23, octubre-diciembre 2001, Año VI, Volumen VI, pp. 59-86 
siglo XVI con las crónicas de descubrimiento y conquista, pasa al XVII y XVIII con las historias naturales y morales y los largos poemas patrióticos criollos y pasa al XIX con el los discursos nacionales, y el ensayo conocido como "de identidad latinoamericana", vincula la reflexión sobre el pasado y la cultura con formas narrativas cercanas a diversos géneros discursivos como la novela de caballería, picaresca, histórica, la poesía, el discurso oral, el artículo periodístico, el relato de viajes, la autobiografía, el epistolario y otros. En el siglo XIX, desde espacios más orgánicamente vinculados al poder, se estructuraron mientras tanto, las bases de una historiografía documental y "científica" acorde a las necesidades de cohesión y hegemonía del proyecto histórico de entonces. En la actualidad, la discusión sobre el tema de los vínculos entre historia y narración o historia y literatura desde la propia disciplina histórica tienen amplia repercusión en publicaciones académicas prestigiosas de varios países latinoamericanos, aunque no deja de ser un dato significativo que ella se centre en aspectos teórico metodológicos y mucho menos en estudios empíricos sobre textos. Lo es también el hecho de que en la convocatoria de la mesa sobre teorías, métodos y enfoques del presente congreso no figure explícitamente como sub tema ni aún en esa modalidad. ${ }^{5}$ Desde los estudios literarios y culturales en cambio, el debate se plantea por el contrario desde los estudios empíricos sobre textos de diversa índole: crónicas e historias naturales coloniales, discursos patrióticos criollos, textos "nacionales" del XIX, textos escritos por mujeres, autobiografías, ensayos, relatos de viaje de los siglos XIX y XX. Estudios cuyas implicaciones para el conocimiento histórico son innegables ${ }^{6}$ y abarcan no 5 Un ejemplo de la orientación del debate en México está en los trabajos que convoca la Revista Historia y Grafía de la Universidad Iberoamericana, cuyo número 24 de 2005 está enteramente dedicado al tema con los títulos siguientes: Luis Vergara Anderson "Discusiones contemporáneas en torno al carácter narrativo del dicurso histórico";Silvia Pappe "Perspectivas multidisciplinarias de la narrativa.Una hipótesis"; Alfonso Mendiola "La inestabilidad de lo real en la ciencia de la historia: ¿argumentativa y/o narrativa?”;Fernando Betancourt Martínez "Historia, ciencia y narración: el orden del decir"; Guillermo Zermeño "Explicar, narrar, mostrar. Danto, Habermas, Foucault y la historia"; Alejandra Labastida Escalante "Otra vuelta de tuerca: búsqueda de lo no narrativo". 6 La perspectiva interdisciplinaria es vigorosamente asumida por las propuestas de investigación que parten de los estudios literarios y culturales, que bien puede ejemplificarse al azar, con las temáticas y disciplinas 
solamente el campo de la historia literaria, sino también el de la historia intelectual, la historia cultural y de las mentalidades. La crítica literaria latinoamericana desde los años treinta del siglo pasado ha desarrollado, con gran productividad, teorías y conceptualizaciones que, al emerger de la realidad local han hecho una consistente contribución a la reflexión sobre la historia, la cultura y la literatura de la región y de las sub regiones que en ella existen. La lectura de los ejemplares estudios de Antonio Cornejo Polar sobre escritura y oralidad en la Conquista y Colonia, a partir del análisis de crónicas ${ }^{7}$ o los de Ángel Rama sobre la elite intelectual de las ciudades latinoamericanas a partir de sus textos clave ${ }^{8}$ es ya un requerimiento indispensable para el historiador latinoamericano. Otro tanto ocurre con los más recientes análisis que -dándole continuidad a aquellos trabajos señeros-se vienen realizando desde los estudios sobre cultura y literatura latinoamericana, cuyo conocimiento, lectura y discusión por los historiadores no haría otra cosa que enriquecer.

En el debate europeo y norteamericano, ciertamente centrado en una epistemología de la historia que tiende a desestimar los estudios empíricos, los autores proponen distintas perspectivas. Entre los clásicos, Paul Veyne con su Cómo se escribe la historia. Ensayo de epistemología de 1971, encabeza a un grupo de importantes historiadores que, con matices significativos postulan el estatuto no científico de la historia, los cuales han sido adoptados por la corriente que ha dado en llamarse "linguisitic turn", cuyos referentes deben buscarse ante

convocadas en encuentros con temáticas como "Las metáforas del viaje y sus imágenes. La literatura de viajeros como problema" organizado en 2002 por la Universidad de Rosario, Argentina, el cual convocó a disciplinas como Historia, Antropología, Letras Clásicas y Modernas, Estudios Culturales, Filosofía, Arquitectura, etc., con temas como la invención de la frontera en América en el discurso de viajeros (Siglos XIX y XX), los usos de la literatura de viajes como fuente histórica, los viajeros y la revolución en América Latina y otros.

7 Cornejo Polar, Antonio, Escribir en el Aire DATOS

8 Rama, Ángel, La ciudad letrada DATOS 
todo en la historiografía y la historia intelectual norteamericana9 . Veyne es considerado como hipercrítico en relación a la práctica dominante en la historia. En esa misma línea, Hayden White, que publicó Metahistoria en 1973, propone la superación de los límites entre la realidad histórica y su representación, haciendo hincapié en las figuras retóricas que organizan todos los modos posibles de narración, para establecer tipologías universales en las cuales inscribir la construcción del discurso histórico ${ }^{10}$. Ambos, fuertes críticos de la opción cientificista de Annales que rechazaba, por superficial, la llamada "historia narrativa"que por lo demás también ha sido adversada por algunos de los teóricos post estructuralistas como Barthes. ${ }^{11}$ White sin embargo, al partir de la constatación bien fundamentada de que toda historia es siempre un relato organizado a partir de figuras que se movilizan por igual en los relatos de ficción, llega a la dudosa conclusión de que no hay distinción alguna entre ficción y disciplina histórica. ${ }^{12}$ No obstante, algunos años después, estos excesos quedaron moderados con una valoración más equilibrada del papel de lo literario en la disciplina histórica que quedó plasmada en escritos como el conocido prólogo que White escribió para la edición en inglés del ensayo ya mencionado de Rancière. ${ }^{13}$ $9 \quad$ Noiriel, Gerard, Sobre la crisis de la historia, Publ. Universitat de Valencia, 1997. 10 En su obra El Contenido de la forma. Narrativa, discurso y representación histórica, Paidos, Barcelona, 1992, Hayden White presenta cuatro tendencias en el debate: la representada por filósfos analíticos anglonorteamericanos (Walsh, Gadiner, Dray,Gallie, Morton White, Danto, Minsk), entre los que el más conocido es Danto; en segundo lugar la de los historiadores orientado hacia las ciencias sociales en la que incluye a Annales (Braudel, Furet, Le Goff, Le Roy-Ladurie) caracterizada por considerar la historiografía narrativa como no científica; En tercer lugar estarían teóricos de la literatura y filósofos de orientación semiológica (Barthes, Foucalult, Derrida, Todorov, Julia Kristeva, Benveniste, Genette, Eco) que han estudiado la narrativa como un código discursivo entre otros y por último, señala la tendencia representada por filósofos de orientación hermenéutica, como Gadamer y Ricoeur que vinculan su estudios de la narración y la narratividad a una conciencia o estructura del tiempo. p 47-48. 11 Idem. p.50

12 Chartier, Roger, "La historia entre relato y conocimiento", Historia y Espacio Departamento de Historia, Universidad del Valle, Cali, Colombia, No. 17, enero-junio 2001 p 185-206 13 White, Hayden, "Prólogo a Rancière", Historia y Grafía, Enero-Junio 1996 
Filósofos como Ricoeur, Michel de Certeau y Jacques Rancière e historiadores como Roger Chartier toman distancia de tales propuestas con una solución integradora que apunta a destacar la doble condición de la historia como conocimiento ("ciencia") y como relato a la vez.

\section{Historia y Narración}

En efecto, si el primer paso en la transformación de la historia en ciencia fue sacar de ella el relato, Ricoeur puso al descubierto que incluso la historia escrita más alejada de la forma narrativa sigue estando ligada a la comprensión narrativa ${ }^{14}$ En la compleja y monumental obra de Paul Ricoeur

...la historia consiste en llevar a cabo una indagación, una inquire, una Forschung. Su intencionalidad específica reside en dicha indagación. ¿Qué quiere decir esto? Que por mucho que sea fruto de la ficción, de la ideología o de una institución, la historia ha de amoldarse a una exigencia específica: el archivo. Desde luego, esa exigencia es una componente de la indagación, pero añade una preocupación inversa a la del juego que caracteriza la ficción literaria: juego con el tiempo, con la distancia, con la perspectiva o con la voz. La indagación, debido a la exigencia del archivo, trata de romper continuamente con la ficción y la ideología del relato, mientras que éste, en la medida en que sigue siendo un relato regido por la elaboración de la trama, no deja, sin embargo, de incorporar nuevos elementos ficticios e ideológicos ${ }^{15}$

14 Vergara, Luis, "Paul Ricoeur y la escritura de la historia", Op.cit.

15 Ricoeur, Paul, "Relato histórico y relato de Ficción”en Historia y narratividad, Introducción de Angel Gabilondo y Gabriel Aranzueque.Paidós I.C.E./UAB. Barcelona, 1999, p. 179-180 
Es decir, existe en la historia tanto el sentido de la indagación con la consecuente exigencia del archivo, como el sentido del juego establecido por su condición inevitable de relato regido por la elaboración de la trama. Esa doble condición de la historia escrita, donde por lo demás quedan de manifiesto los fundamentales postulados de que la escritura de la historia es ella misma histórica, y que el saber en que se funda la cientificidad de la historia se articula mediante ciertas técnicas literarias, ${ }^{16}$ nos lleva a considerar la lectura del texto historiográfico en un doble registro que permite establecer y ponderar cognitivamente la relación y el valor epistemológico de dicha articulación.

En la experiencia empírica con textos historiográfico/literarios, resulta entonces de la mayor importancia, para fines de "afinar" su lectura, familiarizarse con categorías y conceptos que estudian la narración y el relato ${ }^{17}$. Así, la construcción de la trama es la construcción de lo que provee de significación al relato y lo distingue de una mera sucesión. La trama es la productora de significación, la diferencia entre mera sucesión de hechos y configuración de los mismos en el relato, es también la entidad que provee de orientación ideológica al relato. La construcción de la trama es, no hay que olvidarlo, "un mero arquetipo cultural". La otra instancia productora de significación es la lectura, que al confrontar el mundo del texto y el mundo extratextual del lector

16 Véase la nota introductoria de Alfonso Mendiola al Prólogo escrito por White, citado arriba.

17 Siendo que la Teoría Narrativa es un campo vastísimo y complejo, es apreciable lo que estudios como el de Luz Aurora Pimentel aportan en términos de teoría y análisis textuales a no especialistas que se acercan a dicha temática. Pimentel, Luz Aurora, El relato en perspectiva. Estudio de Teoría Narrativa, Siglo XXI Editores-Facultad de Filosofía y Letras UNAM, México, 1998 y El espacio en la ficción, Siglo XXI-UNAM, México D.F. 2001. 
completa y da significación al texto. Además de la trama o configuración y la lectura resulta fundamental la distinción entre historia y discurso (aquí historia es precisamente el "tema" de la trama), entre mundo narrado y narrador, en la que la relación del éste último con el mundo narrado es crucial para comprender la significación del relato. El historiador, -como bien se desprende de los textos de Paul Ricoeur-, tiene "voz" en tanto que es un narrador que se distingue del autor real del mismo modo en que sucede en la novela, ${ }^{18}$ y en su relación con el mundo narrado, que la mayor parte de las veces es, de externidad, a veces se filtran variaciones que es importante detectar, porque esta forma de situar la voz del narrador (dentro o fuera) respecto del mundo narrado es una pista en el esclarecimiento de ese modo histórico y cultural de la escritura de la historia. Así por ejemplo, una voz narrativa inestable en su relación con el mundo narrado tanto en términos espaciales como temporales es una característica del relato que proyecta otros mundos, otros tiempos, otros sujetos sociales o bien un mundo fragmentario. Cuando existe esa inestabilidad o más específicamente una fragmentación vocal (muchas voces) se trata de una característica del siglo XX en el que ciertamente, es difícil tener un concepto o una definición única del mundo. Trascender el plano epistemológico general de la propuesta teórica y metodológica del debate historiográfico y también la que provee la perspectiva interdisciplinaria de los estudios culturales permite afrontar el desafío -para los historiadores- de acercarse a las categorías de la teoría narrativa para comprender mejor esta dimensión del relato histórico así como las implicaciones que dicha comprensión supone para su propia disciplina.

3.Texto histórico y texto literario. Guatemala, las líneas de su mano, y La

18 Véase Ricoeur, Paul, Historia y Narratividad, Op. Cit. P 179 


\section{Patria del Criollo}

El trabajo que se refiere a continuación fue realizado sobre dos textos histórico-literarios de Guatemala escritos y publicados en la segunda mitad del siglo XX, estos son La Patria del Criollo de Severo Martínez Pelaéz de 1970 y Guatemala, las líneas de su mano de Luis Cardoza y Aragón de 1955. Un primer acercamiento obliga a buscar el contexto histórico de producción de ambas obras, el cual, pese a que las separan quince años, está definido por el año 1954, en que ocurre el derrocamiento de la revolución democrática que había comenzado diez años antes; acontecimiento político fundamental en la historia moderna del país, inserto de lleno en el clima internacional de la "guerra fría" aunque articulado históricamente a sus contradicciones internas. En el plano cultural, en ese periodo, surgió entre los sectores desplazados por el derrocamiento la necesidad de un replanteamiento total de la historia, la identidad nacional, y la nación misma. Necesidad que entroncaba con similares preocupaciones en la región latinoamericana, las cuales adquirían forma literaria en obras ensayísticas y novelas de temática nacional y de conflicto social. En el campo literario latinoamericano el periodo corresponde a tensiones no menos significativas entre el modernismo, el realismo social y la "nueva narrativa", que expresaban viejos conflictos no resueltos en la sociedad a los que se sumaban tensiones propias de la modernización emergente. El debate intelectual por su parte se daba entre versiones nuevas de viejas corrientes de pensamiento que resurgían en América Latina, con perspectivas distintas en torno al tema de la identidad y a otros puntuales como el debate en torno a los modos de producción y el relativo al papel social y político del intelectual. Ambas obras son tributarias de ese contexto general. 
Es difícil establecer un orden cronológico a esta serie de tensiones y contradicciones de distinto orden en las que tanto Luis Cardoza y Aragón como Severo Martínez Peláez coincidieron históricamente, aunque cada uno las haya vivido en momentos distintos de su desarrollo. Lo es, porque se trata más de una yuxtaposición que de una secuencia. Bajo criterios de historiografía literaria, las dos obras atestiguan huellas de filiaciones diversas. No obstante, el paradigma estético, epistemológico e ideológico del debate entre realismo social y vanguardias que marcó vivamente el periodo histórico comprendido entre las décadas treinta al cincuenta, constituye un eje alrededor del cual ambas organizan su propuesta, si bien el modo en que se relacionan con él difiere ampliamente. Debate cuya perspectiva, por las particularidades del desarrollo histórico guatemalteco, permaneció vigente por largo tiempo articulado a variados procesos culturales y literarios ilustrando con ello la compleja red de ideologías que configura las mentalidades y la cultura del país.

No es casual que se trate de obras guatemaltecas de la segunda mitad del siglo XX. En el estudio sobre ellas ha interesado especialmente la naturaleza de la relación y el peso específico de la historia, la cultura y la literatura en la definición de las formas de elaboración del discurso historiográfico moderno en Guatemala y por tanto, en la definición de las imágenes que la sociedad guatemalteca ha construido de sí misma en distintos momentos y con distintos fines en ese periodo como antecedente inmediato de lo que son dichas construcciones en el presente actual. Este discurso de la historiografía "nacional", si se la examina bajo ópticas más amplias, remite no solamente a "hechos" puntuales acaecidos y relatados posteriormente, sino a formas de pensar, de usar el lenguaje y de crear imágenes y formas que son históricas, culturales y por supuesto sociales y políticas, incluyendo las que representan la relación conflictiva en y con 
la diversidad. Es decir, remite a las sucesivas y entreveradas ideas de "literatura", "historia" "nación" e "identidad" que una sociedad elabora en el tiempo, generalmente por oposición o en conflicto con otra u otras.

Establecidas históricamente las obras, su contenido y forma se analizan entrelazadamente Ha interesado particularmente desentrañar problemas de construcción y organización de los textos, de enunciación de la o las voces narrativas y de imágenes de la configuración del otro. Es así como se descubre que La Patria del Criollo no se limita a informar distanciadamente sobre el periodo Colonial, sino más bien hace acopio de estrategias narrativas que le permiten hacerlo desde ese tiempo. El narrador del relato adopta una voz conflictiva en la que confluyen la del criollo colonial y la del historiador moderno, siempre en disputa. Este último, atrincherado en el discurso científico, habla con el lenguaje que le es propio (notas al pie de página, abundantes prescripciones de lectura, información erudita). En variadas ocasiones traspasa espacios discursivos y tiempos situándose en los acontecimientos narrados. Este principio en la obra de Martínez que, como se ve, simultáneamente transgrede y ordena los campos de acción del autor, narrador y lector, así como el de los géneros discursivos mismos, contiene en sí y desarrolla por rumbos nuevos, el principio organizador del texto de Cardoza y Aragón. En éste, el narrador asedia sus temas narrativos desde multiplicidad de discursos y simultaneidad de tiempos, si bien bajo un concepto estético distinto. Se trata de un vínculo de acumulación y superación, de sedimentación de tradiciones varias y de diálogo. Debido a que la obra de Cardoza está "contenida" en la de Martínez, que a su vez da respuesta a requerimientos planteados por aquella, puede decirse que La patria del criollo actualiza y hace vigente la impronta de Guatemala, las líneas de su mano. Por su parte, ésta, desde el pasado, plantea a la de Martínez y a su tiempo en 
general, importantes desafíos y retos.

Definida por la coyuntura histórica ${ }^{19}$, más que por el proceso de larga duración (a pesar de que su contenido se refiere a la historia del país desde el periodo precolombino hasta la mitad del siglo XX), la obra de Cardoza y Aragón se ciñe a paradigmas estéticos de su tiempo que combinan la narración de relatos y la descripción de imágenes en una suerte de ensamblaje de crónica de viajes, autobiografía, ensayo poético y ensayo de interpretación, Por el contrario, la de Severo Martínez, con una percepción de largo alcance, capta mejor los lentos desarrollos y la perduración de los procesos históricos. Ello se relaciona con el hecho de que en su construcción literaria se combinan las formas del ensayo "científico" de largo aliento, que tiende a la reflexión de los universales y no de particularidades, con la estructura "pedagógica" de "lecciones" escalonadas y el ensayo de interpretación, sin estar ausentes la biografía, algunos rasgos autobiográficos y la trama novelesca.

El escudriñamiento del principio organizador de los textos estudiados ha puesto de manifiesto la densa carga de tradiciones intelectuales, ideológicas, culturales y literarias que se asientan en los planos profundos de su estructura. En mayor medida de la que pudiera pensarse, las huellas discursivas y las marcas culturales apuntan a formas vinculadas a la visión del mundo del criollo. A pesar y en contradicción con el discurso de denuncia y confrontación que vertebra

19 Aunque Guatemala, las líneas de su mano fue escrita como una síntesis histórica, se inscribe en un proyecto intelectual cuya intención fue explicar e ilustrar la situación del país a la luz de los acontecimientos de 1954 que dieron fin a la revolución democrática de 1944. De este modo, la obra queda estrechamente vinculada a La Revolución Guatemalteca, la obra paralela de Cardoza y Aragón publicada casi simultáneamente a la primera, en la que trata en detalle lo acontecido en los diez años transcurridos entre una y otra fecha. Cardoza y Aragón, Luis, $L a$ Revolución Guatemalteca, Editorial El Pensativo, Guatemala, 1994. Primera edición Fondo de Cultura Económica, México, 1955. 
ambas obras, existe en la elaboración de ciertas imágenes, en la configuración de ciertos espacios y condiciones de la voz enunciativa, formas que corresponden a tradiciones literarias y culturales arraigadas en un pasado "criollo", que paulatinamente y mediando complejas transformaciones, entronca con las elites intelectuales de distintos periodos históricos. Sin embargo, la densa trama de los textos y los ecos de lenguajes y voces enraizadas en ellos -que son los de la clase y el modelo de dominación hegemónico en Guatemala-, no hacen sucumbir a los discursos, saberes y lenguajes populares que las obras también incorporan en tensión con aquellos. La dualidad no hace sino resaltar la enorme complejidad de los procesos textuales y los intrincados caminos por los cuales se ha ido construyendo la reflexión crítica sobre la historia, la cultura y la identidad en Guatemala y en América Latina.

4. Imágenes, descripciones y estrategias narrativas: cómo se escribe la historia moderna en Guatemala ${ }^{20}$.

Nada mejor para ilustrar en que medida el relato de la historia se construye como tal, que detenerse en algunas de las imágenes, descripciones o estrategias narrativas con las que se configura la trama, núcleo de significación fundamental del mismo. Imágenes, descripciones y estrategias que, como ya se ha dicho, responden a modelos culturales que son ellos mismos históricos, políticos, ideológicos. En La Patria del Criollo abundan los ejemplos, dos de ellos me parecen especialmente significativos: la imagen del terremoto en Santiago de Guatemala que es evocado en las primeras páginas y el apartado "Diligencias" que corresponde a uno de

20 Los ejemplos que se presentan en este apartado provienen del estudio previo que he realizado sobre las obras mencionadas, el cual saldrá a la luz próximamente con el título de Árbol de historias. Historia y literatura en Severo Martínez y Luis Cardoza y Aragón. 
los capítulos de la obra, en el que se hace transparente el hecho de que la forma y las estrategias narrativas con que se compone el relato histórico dicen tanto de la propia historia como sus contenidos. En la obra de Cardoza y Aragón igualmente es posible analizar la construcción de imágenes y representaciones de aspectos cruciales de la historia y la sociedad guatemalteca, entre ellas destaca la de la imagen del indígena, lo que es decir, un referente fundamental de las relaciones sociales en la historia del país.

En el primero de los casos, la estructura misma del capítulo IV de la obra de Martínez, titulado "Tierra milagrosa" es en sí misma una lección historiográfica: tras una lectura atenta de la forma en que se organizan los apartados, emerge un poderoso principio ideológico que, a su vez, supone una propuesta respecto del modo de concebir el tiempo y la historia, se trata del principio de vinculación del pasado con el presente, que en La Patria del Criollo resulta fundamental habida cuenta de que la obra se propone fundamentar la perduración de las estructuras socioeconómicas del pasado en el presente de la escritura. Pero también el principio polémico sobre el que descansa la organización del texto encuentra en este capítulo una condición ejemplar: hasta la secuencia de los apartados está organizada de forma tal que los discursos en pugna del cronista criollo y del historiador contemporáneo queden confrontados.

Es así como tras la apertura del capítulo mencionado, con el discurso romántico del criollo sobre el paisaje y la tierra milagrosa, se continúa con una pormenorizada argumentación científica a cargo del historiador/narrador, discurso opuesto al del primero, que replica el modo de concebir la tierra como paisaje a partir de la explicación de los principios de la política agraria colonial. Sin embargo, es el apartado de las diligencias para obtener tierras el que ejemplifica mejor lo 
que aquí quiere destacarse: se trata de lo que podría llamarse un relato intercalado, es decir, un relato que, desviándose del hilo narrativo precedente, cuenta una historia independiente que sin embargo cumple una función en el conjunto de la narración. Se cuenta en él la historia de un terrateniente que quiere obtener tierras y se vale para ello de variados subterfugios e ilegalidades en complicidad con autoridades y en perjuicio de los indios y sus tierras comunales. Para narrar dicha historia el historiador se fundamenta en el análisis de un documento, que -según lo indica él mismo-, no tiene nada de particular y fue escogido al azar entre otros similares y señala también que su trabajo con dicho documento se limitará a subrayar momentos significativos y agregar pocas observaciones y paréntesis. No obstante, al leer con cuidado la historia narrada y seguir con atención los procedimientos implicados en ella, puede advertirse que, lejos de ser un documento común al que se le hacen pocas observaciones, se trata en realidad de un documento paradigmático que es analizado cuidadosa y pormenorizadamente por el historiador quien hace no pocas, sino más bien abundantes observaciones, anotaciones y comentarios. Este recurso que pretende disminuir la importancia del documento y de la intervención del historiador en realidad es un dispositivo discursivo que se encamina a lograr lo contrario de lo que aparenta, pues el objetivo final es que la verdad autónoma de la historia resplandezca en la misma medida en que la singularidad del documento o la intervención del historiado disminuyen. Se trata en resumen de una estrategia de verosimilitud cuyo objetivo es forjar el efecto de verdad en el lector, convencerlo de que el relato verbal que ha leído se apuntala como una verdad objetiva que se dice a sí misma y que no requiere más que una leve intervención del historiador Juegos con el tiempo del relato y el tiempo de la historia narrada, intervenciones paródicas, variadas formas de relación del narrador con los hechos narrados y una fuerte intervención autoritaria del narrador sobre la lectura son otras tantas estrategias que conforman el discurso historiográfico en La Patria 
del Criollo, un discurso que replica desde su condición no ficcional, lo que la novela también pretende: desprenderse de su condición de discurso escrito y pasar como verdad, analogía entre géneros que de alguna manera da cuenta de la historia cultural e intelectual del siglo XX.

En la obra de Cardoza y Aragón es la construcción de la imagen del indígena la que servirá como ejemplo del eco que en esta obra tiene la misma problemática que retomará quince años después La Patria del Criollo: la oposición de dos discursos: el que enfatiza en la paisaje y el que revela la dureza de la vida social; oposición que no hace sino examinar las contradicciones sociales más lacerantes en el país. De esta manera, en la obra de Cardoza y Aragón la inevitable extrañeza del otro es captada por la mirada externa; la casi ausencia de diálogo, en que las escasas palabras del personaje Manuel Tuch son dichas por la voz del narrador y por la construcción de dicha imagen descontextualizada, paradójica y grotesca. Una imagen que es una puesta en escena de las complejidades de la sociedad guatemalteca, la cual se logra haciendo uso de la paradoja y parodia para establecer la máxima contradicción entre el espacio y los personajes que lo habitan. De esta manera, el texto plantea a propósito, un cierto pintoresquismo en las descripciones del país, la ciudad y la casa natal, el cual va acusando gradualmente una cada vez mayor asintonía con los personajes que van surgiendo, casi siempre descritos en términos ingratos.

Manuel Tuch, ese "peón de nuestras tierras" como lo nombra Cardoza y Aragón, surge en la trama del relato como doblemente "personaje", es decir, como personaje de la historia que se narra y como personaje dentro de la historia que se narra, ya que la escena relatada es la de Manuel Tuch vestido, casi disfrazado de cucurucho en una procesión popular en Semana Santa. Ebrio, con guantes blancos sobre sus manos con uñas negras, con un tocado que resbala sobre su 


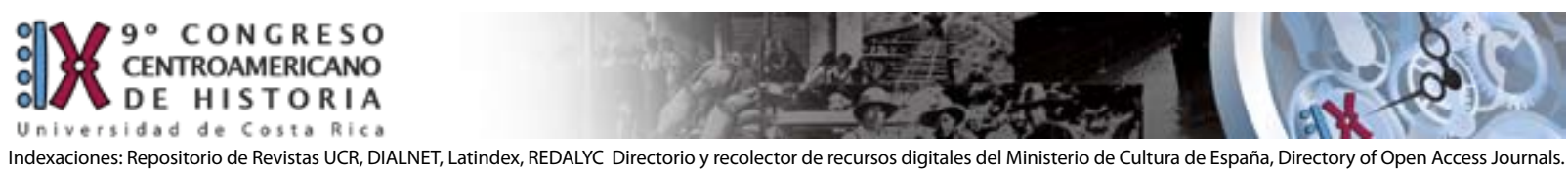

Indexaciones: Repositorio de Revistas UCR, DIALNET, Latindex, REDALYC Directorio y recolector de recursos digitales del Ministerio de Cultura de España, Directory of Open Access Journals. Diálogos Revista Electrónica de Historia ISSN 1409-469X. Número especial 2008. Dirección web: http://historia.fcs.ucr.ac.cr/dialogos.htm

frente y con los zapatos en la mano porque está habituado a caminar descalzo, la representación de la figura del otro queda así plenamente dicha desde la mirada de narrador en toda su radical alteridad y extrañeza.

Puede verse entonces que estos textos fundamentales de la cultura contemporánea guatemalteca aparecen, tras la lectura heterodoxa de lo dicho más allá de lo explícitamente argumentado, como conformados por capas superpuestas de sentidos y significaciones diversas, textos complejos que recogen en sus formas la densidad de la propia historia y que proponen al lector interesado en descubrirlos, múltiples caminos para examinar y reflexionar desde la historia y la literatura, sobre los problemas sociales y humanos que retrataron la sociedad guatemalteca de su tiempo y de cierta forma, también la de este tiempo. 